\title{
TELUSUR GASTRONOMI INDONESIA: MEMBANGUN INTEGRASI DATA GASTRONOMI BERBASIS REMPAH
}

\author{
Muhammad Firnanda ${ }^{12}$ \\ muhammadfirnanda19@gmail.com \\ ${ }^{1}$ Calon Peserta Muhibah Jalur Rempah Perwakilan Kalimantan Tengah \\ ${ }^{2}$ Mahasiswa Pendidikan Sejarah, Universitas Lambung Mangkurat
}

\section{Pendahuluan}

Masyarakat di Indonesia adalah masyarakat heterogen. Artinya terdapat identitas ras, etnis, agama, dan budaya yang beragam. Keberagaman masyarakat di setiap daerah inilah yang menciptakan sebuah kebudayaan, bernama kebudayaan Indonesia. Kebudayan sendiri diketahui secara umum sebagai segala sesuatu yang berkaitan dengan cipta, rasa, karsa, dan hasil karya masyarakat. Kebudayaan menurut E.B. Taylor didefinisikan sebagai kompleks yang mencakup pengetahuan, kepercayaan, kesenian moral, hukum, adat istiadat dan lain kemampuan-kemampuan serta kebiasaan kebiasaan yang didapatkan oleh manusia sebagai anggota masyarakat. ${ }^{1}$ Sehingga kebudayaan memiliki makna yang luas dan menyeluruh dalam kehidupan manusia.

Salah satu wujud kebudayaan yang general di masyarakat Indonesia adalah makanan. Linda Civitello menyebutkan identitas agama, negara, dan etnis adalah hal yang yang terikat erat dengan makanan. ${ }^{2}$ Dengan keberagaman identitas berarti masyarakat Indonesia terikat dengan makanan dan makanan yang beragam. Makanan sendiri adalah artefak (benda) dalam wujud kebudayaan, hal ini dilihat dari arti wujud kebudayaan yang dikemukakan Koentjaraningrat berupa adanya ide, aktivitas dan artefak (benda). Antara makanan dan kebudayaan telah dikaji dalam kajian gastronomi. Gastronomi Menurut Taqwani adalah studi tentang hubungan budaya dengan makanan, gastronomi mempelajari beragam komponen budaya dengan makanan sebagai pusatnya (seni kuliner) yang berbunga dengan budaya. ${ }^{3}$ Sehingga kajian gastronomi Indonesia adalah kajian menyeluruh tentang hubungan budaya dengan makanan di Indonesia yang beragam.

\footnotetext{
${ }^{1}$ Soekanto, S. (2012). Sosiologi Suatu Pengantar: Edisi Revisi. Jakarta: Rajawali Press. Hlm. 148.

2 Sudarwan, I. A., Abdullah, A., \& Maharani, N. (2019). Wacana Keislaman dalam Antropologi Kuliner Indonesia. Jurnal Kajian Jurnalisme, 3(1), 107-121. Hlm. 117.

${ }^{3}$ Sani, M. R., Alia, M. N., \& Riyadi, D. (2016). Sate Padang Sumatera Barat sebagai Gastronomi Unggulan di Indonesia. Gastronomy Tourism Journal, 3(1), 274-282. Hlm. 277.
} 
Namun perlu diketahui bahwa kebudayaan akan terus berkembang, karena kebudayan bersifat dinamis. Menurut Melville kebudayaan bersifat dinamis dan setiap kebudayaan mengalami perubahan disamping bersifat stabil. ${ }^{4}$ Dalam gerak kebudayaan, kebudayaan tak ada yang statis..$^{5}$ Akibatnya penulis menemukan berbagai masalah, tantangan, dan peluang datang dalam gastronomi Indonesia.

Dalam Pasal 32 ayat (1) Undang-Undang Dasar Negara Republik Indonesia Tahun 1945 mengamanatkan bahwa "Negara memajukan kebudayaan nasional Indonesia di tengah peradaban dunia dengan menjamin kebebasan masyarakat dalam memelihara dan mengembangkan nilai-nilai budayanya". Dengan amanat ini perlu untuk menghadapi masalah, tantangan, dan peluang dalam gastronomi Indonesia. Cara menghadapinya adalah dengan ikut serta dalam pemajuan kebudayaan. Pemajuan kebudayaan adalah upaya meningkatkan ketahanan budaya dan kontribusi budaya di tengah peradaban dunia melalui pelindungan, pengembangan, pemanfaatan, dan pembinaan kebudayaan.

Dari paparan di atas ditemukan masalah untuk melakukan pemajuan kebudayaan terkait gastronomi Indonesia, yakni belum adanya data terpadu (integrasi) terkait gastronomi Indonesia. Dalam konteks lintasan sejarah, gastronomi Indonesia hari ini sedikit banyak dipengaruhi oleh bangsa asing yang datang ke kerajaan-kerajaan di Nusantara (Sebelum menjadi Hindia-Belanda; Indonesia) karena rempah Nusantara, namun belum ada data gastronomi berbasis rempah. Akhirnya, perlu disederhanakan masalah agar menjadi terarah, penulis menyederhanakan menjadi bagaimana membangun integrasi data gastronomi Indonesia berbasis rempah dengan cara menelusurinya. Integrasi data yang terkumpul diharapkan mampu membantu mengeksekusi pemajuan kebudayaan.

\section{Gastronomi Bagian Pengetahuan Tradisional}

Dalam sepuluh objek pemajuan kebudayaan terdapat objek pengetahuan tradisional. Secara harfiah, pengetahuan tradisional berarti kepandaian masyarakat tradisional. Pengetahuan tradisional merupakan hasil pengalaman adaptasi dengan lingkungan sekitar yang menjadi kebiasaan dan diwariskan. Menurut Ridwan pengetahuan tradisional adalah informasi yang dikembangkan oleh suatu masyarakat tertentu yang didasarkan kepada pengalaman dan adaptasi terhadap budaya serta lingkungan setempat, yang terus berkembang seiring berjalannya waktu. ${ }^{6}$

\footnotetext{
${ }^{4}$ Soekanto, op. cit. Hlm. 157.

${ }^{5}$ Soekanto, op. cit. Hlm. 165.

${ }^{6}$ Ridwan, A. M. (2020). Perlindungan Pengetahuan Tradisional Terkait dengan Keanekaragaman Hayati di Indonesia. Jurnal Pemuliaan Hukum, 1(1). Hlm. 99.
} 
Gastronomi menjadi bagian pengetahuan tradisional karena berhubungan dengan aktivitas manusia dengan latar belakang pengetahuan akan adaptasi lingkungan (utamanya) terhadap makanan. Kajian gastronomi oleh Santich B sangat interdisipliner berkaitan dengan refleksi dari sebuah sejarah, dampak budaya, dan suasana lingkungan terhadap makanan dan minuman menjadi penting bagi masyarakat dan jasa makanan. ${ }^{7}$

\section{Konsep Telusur Gastronomi Indonesia}

Dewasa ini, Indonesia memiliki 34 provinsi sebagai wujud dari otonomi daerah. Konsep yang penulis pikirkan, telusur gastronomi Indonesia bukan dilakukan dengan cara mendata makanan secara wilayah administrasi sekarang. Jika dilakukan, maka efisiensi akan berkurang. Sehingga telusur gastronomi ini wajib memperhatikan aspek sejarah dan dilaksanakan di titik-titik peradaban rempah masa lalu.

Kajian gastronomi seyogyanya menimbang aspek geohistori, mengenali makanan dengan bantuan ilmu sejarah dan ilmu geografi atau bisa disebut geografi sejarah. Kajian geografi sejarah adalah mempelajari tentang manusia, keadaan fisik, fiksi, dan berkaitan sejarah dengan fakta-fakta keadaan geografi di masa lampau. ${ }^{8}$ Geohistori mengkaji bagaimana keadaan lingkungan di masa lampau dalam peristiwa sejarah maupun perubahan lingkungan, bahkan pembahasan geohistori juga mencari munculnya kebudayaan. Ini sebabnya dalam menelaah geohistori utamanya menggunakan kajian geohistori.

Setelah aspek penting sejarah dan geohistori, konsep telusur ini harus memerhatikan aspek pada kajian sosiologi, antropologi kuliner, dan teknologi pangan. Sosiologi untuk mengkaji masyarakat di titik-titik peradaban rempah, antropologi kuliner untuk mengkaji bagaimana manusia dan pemanfaatan rempah untuk makanan, dan kajian teknologi pangan untuk mengkaji makanan berbasis rempah.

Secara menyeluruh sumber daya manusia utama yang diperlukan dalam telusur gastronomi adalah sejarawan, antropolog, sosiolog, geografer, dan ahli teknologi pangan. Data yang dikumpulkan adalah makanan berbasis rempah dan makanan yang hadir karena peradaban rempah. Dalam satu data makanan bisa saling terkait satu sama lain, namun substansi datanya berisi sejarah, pengaruh geografis, perubahan, eksistensi, cara mengolah, dan peruntukan penyajian. Data yang terkumpul akan diintegrasikan secara digital,

\footnotetext{
${ }^{7}$ Sani, et al., loc. cit.

${ }^{8}$ Effendi, R. (2020). Geografi dan Ilmu Sejarah (Deskripsi Geohistori untuk Ilmu Bantu Sejarah). Banjarmasin: Pendidikan Sejarah FKIP ULM. HIm. 113.
} 
dipublikasikan, dan dimanfaatkan untuk pemajuan kebudayaan (pelindungan, pengembangan, pemanfaatan, dan pembinaan).

\section{Kesimpulan dan Saran}

Makanan dalam aspek gastronomi Indonesia adalah makanan yang beragam karena memiliki keragaman identitas. Indonesia sendiri memiliki sejarah yang panjang terkait rempah sehingga memiliki beragam makanan menggunakan rempah. Namun, gastronomi Indonesia khususnya berbasis rempah belum memiliki data yang integrasi sehingga sulit untuk melakukan pemajuan kebudayaan. Permasalahan dijawab dengan mengadakan telusur gastronomi Indonesia ke titik-titik peradaban rempah masa lalu untuk mengumpulkan data. Sehingga nantinya data tersebut utamanya dapat digunakan untuk pemajuan kebudayaan.

Saran penulis terhadap telusur gastronomi Indonesia untuk membangun integrasi data berbasis rempah, yakni dilaksanakan dengan kerjasama civitas akademik, publikasi data secara internasional, data diolah menjadi film atau short film, dan dilakukan secara berkesinambungan. 


\section{Daftar Pustaka}

Effendi, R. (2020). Geografi dan Ilmu Sejarah (Deskripsi Geohistori untuk Ilmu Bantu Sejarah). Banjarmasin: Pendidikan Sejarah FKIP ULM.

Ridwan, A. M. (2020). Perlindungan Pengetahuan Tradisional Terkait dengan Keanekaragaman Hayati di Indonesia. Jurnal Pemuliaan Hukum, 1(1).

Sani, M. R., Alia, M. N., \& Riyadi, D. (2016). Sate Padang Sumatera Barat sebagai Gastronomi Unggulan di Indonesia. Gastronomy Tourism Journal, 3(1), 274-282.

Soekanto, S. (2012). Sosiologi Suatu Pengantar: Edisi Revisi. Jakarta: Rajawali Press

Sudarwan, I. A., Abdullah, A., \& Maharani, N. (2019). Wacana Keislaman dalam Antropologi Kuliner Indonesia. Jurnal Kajian Jurnalisme, 3(1), 107-121 